\title{
A ELEVAÇÃO INJUSTIFICADA DE PREÇOS COMO PRÁTICA ABUSIVA: FUNDAMENTAÇÃO E CRITÉRIOS PARA SUA IDENTIFICAÇÃ̃O
}

Talden Farias

Graduado em Direito pela Universidade Estadual da Paraíba. Mestre em Ciências Jurídicas pela Universidade Federal da Paraíba. Doutor em Recursos Naturais pela Universidade Federal de Campina Grande.

taldenfarias@gmail.com

\author{
Vinícius Salomão de Aquino \\ Advogado. Mestre em Ciências Jurídicas pela UFPB e \\ especialista em Direito Civil-Constitucional pela ESMA- \\ PB/UFPB. Autor de trabalhos nas áreas de Direito \\ Ambiental e Urbanístico. \\ viniciusdeaquino@hotmail.com
}

RESUMO: O presente artigo tem por objetivo debater as práticas abusivas ao consumidor, com enfoque no inciso X do art. 39 do Código de Defesa do Consumidor que veda a elevação de preços sem justa causa. $\mathrm{O}$ tema é analisado a partir da compreensão das bases da teoria do abuso de direito e do subsistema do abuso de direito presente na norma consumerista, aliada ao estudo de decisões judiciais que abordaram a temática. Conclui-se que a intervenção do Estado é válida para garantir a harmonia nas relações de consumo, inclusive quanto ao combate do aumento injustificado de preços em detrimento de uma liberdade absoluta ao fornecedor que ensejaria grandes injustiças sociais a partir dos critérios assentados neste artigo.

PALAVRAS-CHAVE: Direito do Consumidor. Direito Econômico. Teoria do abuso de direito. Práticas abusivas.

Unjustified price rises as abusive practice against consumers: legal grounds and criteria for its identification

\begin{abstract}
This article aims to debate the abusive practices against consumers, with focus on the subsection $\mathrm{X}$ of the article 39 from the Consumer Defense Code that prohibits unjustified price rises. The subject is analyzed from the basic structure of the theory of abuse of right and the subsystem of abuse of right that exists in the consumer law, combined with the study of judicial decisions that tackles this thematic. The conclusion is that the state intervention in the economy is valid to guarantee harmony in the consumerist relationships, even when it regards to contest unjustified price rises over the absolute liberty given to the supplier that could create big social injustices according to the criteria fixed in this article.
\end{abstract}

KEYWORDS: Consumer Law. Economic Law. Theory of abuse of right. Abusive practices.

\section{INTRODUÇÃ̃o}

O processo pelo qual os produtos e serviços são disponibilizados pelos fornecedores ao mercado consumidor pode ser dividido em duas etapas. A primeira engloba as práticas de pro- 
dução que compreendem a montagem, criação, construção e transformação dos bens de consumo, a segunda corresponde às práticas comerciais quando ocorre a comercialização destes, nela estão inclusas atividades como a oferta e o marketing visando a sua aquisição pelo consumidor final, bem como os atos pós-venda.

O Código de Defesa do Consumidor (Lei n. 8.078/90), objetivando conferir uma ampla proteção ao consumidor em todas as fases da relação de consumo, reservou um capítulo específíco no Título I "Dos Direitos do Consumidor” para regular as práticas comerciais. O seu Capítulo V (arts. 29 a 45) disciplina questões relativas à oferta, publicidade, práticas abusivas, cobrança de dívidas e bancos de dados de consumidores. Os fornecedores, às vezes sistematicamente, adotam práticas que ferem o princípio da boa-fé nas relações de consumo antes, durante e após a compra ser efetuada, como acontece nos casos de publicidade abusiva direcionada às crianças, imposição de venda casada e inclusão do consumidor de maneira injustificada em cadastros de proteção ao crédito.

O presente artigo é dedicado ao exame das práticas abusivas, apresentando as suas bases jurídicas, conceitos e âmbito de proteção. O foco central do estudo é a análise do inciso X do art. 39 do diploma consumerista que considera a elevação sem justa causa do preço de produtos ou serviços uma prática abusiva, procurando compreender a razão de sua inclusão no rol de práticas condenáveis e em quais casos ela estará caracterizada através da análise da doutrina, sua relação com o direito econômico, comparação com instituto do price gouging e de decisões judiciais sobre o tema. Trata-se de pesquisa doutrinária e documental, que também se pauta pela análise de julgados específicos do assunto.

\section{Práticas abusivas e a teoria do abuso de direito}

A concepção de práticas abusivas está relacionada com o desenvolvimento da teoria do abuso de direito. O abuso ou excesso, segundo lição de Fernando Augusto Cunha Sá, ocorre quando o exercício de um direito está em contrariedade com o elemento axiológico da prerrogativa conferida ${ }^{1}$. Esta distorção pode causar danos a terceiros mesmo sem afrontar diretamente um dispositivo legal, de tal forma que os juristas constataram que o exercício de um direito subjetivo de modo excessivo não deveria ser respaldado pelo direito e as pessoas prejudicadas poderiam pleitear a interrupção do exercício do direito de forma abusiva, bem como a reparação por eventuais danos sofridos.

Registre-se que o abuso de direito não se confunde com ato ilícito. Heloísa Carpena esclarece que neste o sujeito viola diretamente o comando legal (inobservância de limites lógicoformais), ao passo que no abuso o sujeito aparentemente age no exercício de seu direito, todavia, há uma violação dos valores que justificam o reconhecimento deste mesmo direito pelo ordenamento. $^{2}$

Eva Stiner aponta que a doutrina do abuso de direito foi desenvolvida nos tribunais franceses no final do século XIX. Entre os julgados mais célebres que ajudaram na formação da tese jurídica destacados pela autora estão o caso Doerr decidido em 1855 pela Corte de

CUNHA DE SÁ, Fernando Augusto. Abuso do direito. Coimbra: Almedina, 2005, p. 625

2 MELLO, Heloisa Carpena Vieira de. O abuso do direito no Código de 2002: relativização de direitos na ótica civil constitucional. In: TEPEDINO, Gustavo (Org.). A parte geral do novo código civil: estudos na perspectiva civilconstitucional. 2. ed. rev. atual. Rio de Janeiro : Renovar, 2003. p. 381 
Apelações de Colmar e o Coquerel v. Clément-Bayard apreciado pela Corte de Cassação em $1915 .^{3}$

O caso Doerr ficou conhecido como "o caso da falsa chaminé”, o réu havia construído uma chaminé falsa na sua casa com o propósito de restringir o acesso do seu vizinho, autor da ação, à luz solar na sua residência. A corte de Apelações de Colmar decidiu que o uso do direito de propriedade com o único propósito de prejudicar seu vizinho seria proibido, não podendo ser justificado nem pelo caráter absoluto daquele direito, ordenando, ao final, que o réu demolisse as chaminés falsas.

No caso Coquerel v. Clément-Bayard, Whereupon Coquerel construiu altas cercas de madeira medindo entre dez e onze metros com pontas de metal de dois a três metros cada na divisa da sua propriedade com a de Clément-Bayard como forma de pressioná-lo a aceitar o elevado preço que ele cobrava para vender o seu terreno. Estas estruturas representavam um grande perigo, haja vista que no terreno de Clément-Bayard havia um hangar de dirigíveis que passaram a ter dificuldade para pousar, principalmente quando os ventos estavam fortes. Após um dos dirigíveis de Clément-Bayard ser atingido por uma das pontas de metal, foi proposta uma ação judicial para que Whereupon Coquerel derrubasse as cercas e ressarcisse o seu prejuízo ${ }^{4}$. A Corte de Cassação, órgão de cúpula da Justiça Judiciária francesa, manteve a decisão das instâncias inferiores que consideraram Whereupon Coquerel culpado por abuso de direito e determinaram a demolição das estruturas e o pagamento de indenização pelos danos causados. $\mathrm{O}$ argumento de que a construção das cercas era necessária para a garantia do seu direito à propriedade não vigorou, a corte entendeu que, mesmo legítima a construção de uma cerca ao redor da propriedade, seria inadmissível o modo que ele foi feito por colocar em risco, sem justificativa plausível, os dirigíveis do seu vizinho.

Diante dos casos apresentados, percebe-se que o direito só deve ser protegido quando exercido de forma leal em consonância com o princípio da boa-fé, que é um dos princípios da Política Nacional das Relações de Consumo segundo o art. $4^{\circ}$, III do Código de Defesa do Consumidor. Empresas e comerciantes não podem simplesmente alegar que estão exercendo a sua autonomia privada ou apontar a inexistência de norma que considere a sua conduta ilegal para praticar atos visando o aumento dos seus lucros e sua expansão no mercado em detrimento do bem-estar dos consumidores.

$\mathrm{O}$ fato de o consumidor consentir com o ato abusivo ao adquirir o produto não tem o condão de suprir a sua abusividade. A autonomia privada não pode ser mais considerada como um dogma para as relações civis, principalmente com o advento da releitura do Direito Civil à luz da Constituição. Conforme lição de Gustavo Tepedino, essa mudança de entendimento representa a incorporação de valores não-patrimoniais, principalmente a dignidade da pessoa humana, o desenvolvimento da sua personalidade, direitos sociais e a justiça distributiva, objetivos pelos quais os agentes econômicos também devem cooperar para a sua consecução. ${ }^{5}$

As práticas abusivas enfraquecem ainda mais o consumidor, coagindo-o muitas vezes a adquirir produtos que não desejava ou pagar preços exorbitantes por serviços básicos. Os fornecedores podem ser condenados a ressarcir os danos causados por essas práticas, mesmo quando não tinham a intenção deliberada de tirar proveito delas. Nesse sentido, o Enunciado 37, da I Jornada de Direito Civil promovido pelo Conselho da Justiça Federal aduz que: “A

STEINER, Eva. French Law : A Comparative Approach. New York : Oxford University Press, 2010. p. 391

4 CUETO-RUA, Julio C. Abuse of Rights. Louisiana Law Review. Baton Rouge, v. 35, n. 5, pp. 965-1013, 1975. Disponível em <http://digitalcommons.law.lsu.edu/lalrev/vol35/iss5/3 2 . Acesso em: 19 ago. 2015.

5 TEPEDINO, Gustavo. Temas de Direito Civil. ed $4^{a}$. Rio de Janeiro : Renovar, 2008. p. 23 
responsabilidade civil decorrente do abuso do direito independe de culpa e fundamenta-se somente no critério objetivo-finalístico".

Com efeito, o Diploma Consumerista consagrou a responsabilidade objetiva como regra geral das relações de consumo, o que abarca tanta a aquisição de produtos quanto de serviços ${ }^{6}$. Essa opção decorre do reconhecimento da hipossuficiência do consumidor no contexto das relações de consumo, cabendo destacar nesse sentido que a Constituição Federal de 1988 alçou a defesa deste, no art. 170, V, à condição de princípio da ordem econômica.

\section{Práticas abusivas ao CONSUMidor}

O Código de Defesa do Consumidor incorporou ao seu texto a teoria do abuso de direito para tratar das cláusulas contratuais, práticas comerciais e a publicidade, formando um subsistema do abuso de direito abrangendo essas três órbitas que tem como escopo assegurar que a prática desses atos não desvie da sua finalidade. ${ }^{7}$

$\mathrm{O}$ art. 39 da lei consumerista traz um rol de práticas abusivas sem, contudo, apresentar uma definição ou parâmetros específicos para auferir se certa prática pode ser considerada abusiva. Bruno Miragem, ao discorrer sobre a técnica legislativa utilizada, afirma que ela concebe o instituto com base na boa-fé informadora das relações de consumo, bem como visa utilizar os usos e costumes comerciais como fonte de deveres para o fornecedor. ${ }^{8}$ Herman Benjamin define prática abusiva de maneira sucinta e clara, ela seria qualquer prática que está em "desconformidade com os padrões mercadológicos da boa conduta em relação ao consumidor." 9

No contexto europeu, a Diretiva 2005/29/CE do Parlamento Europeu e do Conselho da União Europeia de 11 de Maio de 2005 dispõe sobre as práticas comerciais desleais das empresas face aos consumidores no mercado interno. $\mathrm{O}$ art. $5^{\circ}$ da diretiva indica que um ato ou omissão será definido como prática comercial é desleal se: ${ }^{10}$
a) For contrária às exigências relativas à diligência profissional;
b) Distorcer ou for susceptível de distorcer de maneira substancial o comportamen- to económico, em relação a um produto, do consumidor médio a que se destina ou que afecta, ou do membro médio de um grupo quando a prática comercial for desti- nada a um determinado grupo de consumidores.

\footnotetext{
6 Art. 12. O fabricante, o produtor, o construtor, nacional ou estrangeiro, e o importador respondem, independentemente da existência de culpa, pela reparação dos danos causados aos consumidores por defeitos decorrentes de projeto, fabricação, construção, montagem, fórmulas, manipulação, apresentação ou acondicionamento de seus produtos, bem como por informações insuficientes ou inadequadas sobre sua utilização e riscos. [..]

Art. 13. O comerciante é igualmente responsável, nos termos do artigo anterior, quando: I - o fabricante, o construtor, o produtor ou o importador não puderem ser identificados; II - o produto for fornecido sem identificação clara do seu fabricante, produtor, construtor ou importador; III - não conservar adequadamente os produtos perecíveis. [..]

Art. 14. O fornecedor de serviços responde, independentemente da existência de culpa, pela reparação dos danos causados aos consumidores por defeitos relativos à prestação dos serviços, bem como por informações insuficientes ou inadequadas sobre sua fruição e riscos.

7 FERNANDES NETO, Guilherme. Cláusulas, prática e publicidades abusivas. $1^{\mathrm{a}}$ ed. São Paulo : Atlas. 2012. p. 112-113.

8 MIRAGEM. Bruno. Curso de Direito do Consumidor. $7^{\text {a }}$ ed. rev. atual. e ampl. - São Paulo: Editora Revista dos Tribunais, 2018. p. 317.

9 GRINOVER, Ada Pellegrini; BENJAMIN, Antônio Herman V.... [et al.]. Código brasileiro de defesa do consumidor: comentado petos autores do anteprojeto. 11. ed. Rio de Janeiro: Forense, 2017. p. 375

10 UNIÃO EUROPEIA. Directiva 2005/29/CE do Parlamento Europeu e do Conselho da União Europeia de 11 de Maio de 2005. Disponível em: <http://eur-lex.europa.eu/legal-content/PT/TXT/ ?uri=uriserv:OJ.L_.2005.149.01.0022.01.POR>. Acesso em: 21 ago. 2015.
} 
O rol de práticas abusivas elencado no art. 39 é meramente exemplificativo, se as práticas abusivas se restringissem àquelas contidas no dispositivo, o instituto ficaria engessado e não conseguiria atingir as suas finalidades. A utilização de conceitos fluidos é ideal, pois possibilita uma adaptação às constantes inovações do mercado para lucrar em cima da fragilidade do consumidor.

Mais exemplos de práticas abusivas também estão previstos em outros dispositivos normativos, o Decreto ${ }^{\circ}$ 2.181, de 20 de março de 1997 que dispõe sobre a organização do Sistema Nacional de Defesa do Consumidor - SNDC Consumidor - prevê a possibilidade da Secretaria Nacional do Consumidor expedir atos administrativos, visando a fiel observância das normas de proteção e defesa do consumidor. A título de exemplo, a Secretaria de Direito Econômico do Ministério da Justiça editou Portaria SDE no 49 de 12/03/2009 que considera abusiva, no serviço de atendimento ao consumidor por telefone, no âmbito dos serviços regulados pelo Poder Público Federal, dentre outras práticas, recusar ou dificultar, quando solicitado pelo consumidor ou por órgão competente, a entrega da gravação das chamadas efetuadas para o Serviço de Atendimento ao Consumidor, no prazo de 10 dias.

Um aspecto fundamental para compreensão do âmbito de proteção conferido pelo Código de Defesa do Consumidor contra as práticas abusivas é o conceito de consumidor aplicável. $\mathrm{O}$ art. inaugural (art. 29) do capítulo "Das Práticas Comerciais" assinala que: "Para os fins deste Capítulo e do seguinte, equiparam-se aos consumidores todas as pessoas determináveis ou não, expostas às práticas nele previstas."

O Código de Defesa do Consumidor apresenta múltiplos conceitos, além daquele insculpido no art. $2^{\circ}$, caput, o art. $2^{\circ}$, parágrafo único, 17 e 29 trazem três outros conceitos de consumidor por equiparação. Herman Benjamin relata que o conceito do art. 29 integrava o corpo da definição central de consumidor contida no art. $2^{\circ}$, caput. Contudo, o lobby empresarial que queria suprimir esse acréscimo, interessado numa definição menos abrangente, forçou que ele fosse deslocado para o art. 29. No entanto, não houve qualquer prejuízo com a fragmentação do conceito. Desta forma, o consumidor também será aquele que está exposto às práticas comerciai, não sendo exigível que ele sofra danos para alcançar tal condição. ${ }^{11}$

\section{ART. 39, X: EleVAR SEM JUSTA CAUSA O PREÇO DE PRODUTOS OU SERVIÇOS}

O inciso em destaque não fazia parte da redação original do art. 39. Ele foi acrescentado pela Lei n. 8.884 (antiga lei do CADE) em 1994. Rizzatto Nunes enfatiza que esta modalidade de prática abusiva seria pós-contratual, só ocorrendo depois da aceitação da oferta, antes disso o fornecedor estaria livre para aumentar o preço segundo a sua vontade, e um resquício da época em que os preços eram controlados ou tabelados no Brasil. ${ }^{12}$

Todavia, o entendimento exposto pelo desembargador aposentado do Tribunal de Justiça de São Paulo não corresponde ao real alcance do dispositivo legal. Inicialmente, cumpre salientar que a prática abusiva é pré-contratual tendo o intuito de impedir que o consumidor seja compelido a adquirir bens ou serviços por um preço exorbitante. A intenção do legislador, segundo magistério de André Ramos Tavares, foi exigir uma justa causa para que o fornecedor

\footnotetext{
${ }^{11}$ GRINOVER, Ada Pellegrini; BENJAMIN, Antônio Herman V.... [et al.]. Código brasileiro de defesa do consumidor: comentado petos autores do anteprojeto. 11. ed. Rio de Janeiro: Forense, 2017. p. 272

12 NUNES, Luiz Antônio Rizzatto. Curso de Direito do Consumidor. 4. ed. rev. São Paulo: Saraiva, 2009. p. 513
} 
possa aumentar o preço do produto, com a economia estabilizada qualquer aumento acima dos índices inflacionários pode gerar uma presunção de falta de justa causa. ${ }^{13}$

A concepção de que o fornecedor estaria completamente livre para definir os valores dos seus produtos está equivocada. Qualquer atividade econômica deve ser exercida em harmonia com os interesses sociais, o art. $173, \S 4^{\circ}$ da Constituição Federal declara que: "lei reprimirá o abuso do poder econômico que vise à dominação dos mercados, à eliminação da concorrência e ao aumento arbitrário dos lucros.” Evidencia-se que no Brasil não prevalece um liberalismo puro, a Constituição outorga ao Estado a possibilidade de intervir na economia de modo repressivo para garantir a justiça social.

O princípio da livre concorrência (art. 170, IV, CF) não implica na total liberdade da empresa em conduzir seus negócios conforme seus próprios interesses, na verdade, ela visa proporcionar um ambiente justo para as atividades econômicas, visando proporcionar a todos liberdade de comércio, liberdade de escolha e acesso aos mercados. ${ }^{14}$

José Geraldo Brito Filomeno acentua que a defesa da ordem econômica tem como razão final a proteção dos interesses e direitos dos consumidores, haja vista que estes são os destinatários finais de tudo que é produzido no mercado. ${ }^{15} \mathrm{O}$ consumo é parte essencial do dia-a-dia das pessoas, ele não é uma mera liberalidade, bens e serviços precisam ser adquiridos para exercer a plenitude de seus direitos. Os fornecedores não podem se aproveitar da sua posição dominante e abusar da necessidade das pessoas para obter lucros cada vez mais altos.

Neste sentido, a Lei n. 12.529/2011, que estrutura o Sistema Brasileiro de Defesa da Concorrência e dispõe sobre a prevenção e repressão às infrações contra a ordem econômica (substituindo a antiga lei do CADE, que inserira o inciso X no art. 39 do Código de Defesa do Consumidor), no seu art. 36 estabelece que o aumento arbitrário de lucros constitui infração da ordem econômica. ${ }^{16}$

Afinal, quais seriam as causas que justificariam um aumento no preço de produtos e serviços? João Batista de Almeida sugere que a justa causa para a elevação pode decorrer do aumento de preços da matéria-prima, alta considerável nos salários dos empregados ou outra causa que efetivamente reflita no custo final do produto ou serviço. ${ }^{17}$ Pode-se acrescentar a essa lista a escassez de matéria-prima, incorporação de característica ao produto que melhore a sua qualidade e fluxos cambiais acentuados, dentre outras situações.

Não há um critério fixo para delimitar quando estará caracterizada a existência de uma prática abusiva, já que boa parte das hipóteses trazidas no diploma consumerista estão fundadas em conceitos jurídicos indeterminados, a exemplo da "justa causa" para elevar o preço dos produtos. Buscando esclarecer a aplicação da proteção instituída pelo Código de Defesa do Consumidor, Bruno Miragem aponta três critérios interpretativos para elucidar a avaliação dos casos concretos: 1) Anormalidade ou excesso do poder de negociação do fornecedor; 2) $\mathrm{O}$ impacto coletivo da prática observada, sem ignorar a possibilidade dela causar danos para

\footnotetext{
13 TAVARES, André Ramos. Direito constitucional econômico. 2.ed. São Paulo: Ed. Método, 2006. p. 271

${ }^{14}$ BUCHAIN, L. C. Os objetivos do direito da concorrência em face da ordem econômica nacional. Cadernos do Programa de Pós-Graduação em Direito - PPGDIR./UFRGS, v. 9, p. 225-262, 2014. p. 239

15 FILOMENO, José Geraldo Brito. Manual de direitos do consumidor. 9a ed. São Paulo: Atlas 2007. p. 64

${ }^{16}$ Art. 36. Constituem infração da ordem econômica, independentemente de culpa, os atos sob qualquer forma manifestados, que tenham por objeto ou possam produzir os seguintes efeitos, ainda que não sejam alcançados: [..]

III - aumentar arbitrariamente os lucros;

17 ALMEIDA, João Batista de. A proteção jurídica do consumidor. $7^{\text {a }}$ ed. São Paulo: Saraiva, 2009. p. 129
} 
consumidores individualmente considerados; 3) violação da boa-fé. ${ }^{18}$ Desse modo, podemos afirmar que haverá elevação de preço sem justa causa quando o fornecedor abusar do seu poder de negociação ou impor condição que destoa do padrão da economia, a alta no preço for capaz de trazer prejuízos aos consumidores e violar o princípio da boa-fé, o qual deve nortear todas as relações civis e consumeristas.

\section{PRICE GOUGING}

Price gouging é o termo utilizado, principalmente nos Estados Unidos, para descrever as ações de vendedores que, nas proximidades de uma situação emergência como furacões ou grandes incêndios, majoram significativamente os preços de produtos essenciais para lidar com a emergência de modo desproporcional com os eventuais aumentos nos custos. ${ }^{19}$

Trinta e quatro estados americanos possuem leis "anti-gouging", alguns chegam a considerar a prática um ilícito penal. Cada Estado regula de forma independente a matéria, indicando o período em que a lei será aplicável, os itens para os quais as determinações serão válidas e o aumento máximo que cada produto pode receber. A título de exemplo o estado da Flórida veda aumentos bruscos nos preços de commodities e aluguéis. A legislação local pressupõe que sejam ilegais os aumentos superiores a $25 \%$ em relação à média praticada nos 30 dias anteriores à decretação do estado de emergência. ${ }^{20}$

Nessas situações de calamidade pública, a população atingida fica extremamente vulnerável ao ter serviços básicos supridos e a necessidade de comprar remédios, alimentos, água e demais produtos necessários para manter a subsistência, justificando assim a vigência dessas normas especiais. Esta situação é análoga aos casos de hipervulnerabilidade, ${ }^{21}$ destacados por Claudia Lima Marques, relativos às pessoas doentes e com necessidades especiais para os quais os parâmetros de proteção devem ser mais qualificados.

Desse modo, seguindo essa linha de raciocínio, ao aferir se um fornecedor incorreu na prática abusiva de aumento injustificado do preço de bens ou serviços prevista no Código de Defesa do Consumidor, dever-se-á avaliar de forma mais criteriosa e rígida quando o produto comercializado for indispensável para o gozo de direitos fundamentais como alimentos e remédios. Destarte, a tolerância em ralação ao percentual de aumento aceitável para um produto supérfluo como uma bolsa ou um relógio poderá ser maior.

\section{ANÁLISE DE DECISÕES JUDICIAIS}

A seguir serão expostas algumas decisões judiciais que enfrentaram a questão da prática abusiva por elevação injustificada de preços com o intuito de examinar quais são os parâmetros adotados pelo Poder Judiciário nesses casos e melhor compreender o instituto, identificando quais foram os critérios utilizados para constatar a existência da prática e as soluções dadas para cada caso concreto.

${ }^{18}$ MIRAGEM, Bruno. O ilícito e o abusivo: propostas para uma interpretação sistemática das práticas abusivas nos 25 anos do Código de Defesa do Consumidor. Revista de Direito do Consumidor, v. 104, p. 99-130, 2016.

19 ZWOLINSKI, Matt. The ethics of price gouging. Business Ethics Quarterly, v. 18, n. 03, pp. 347-378, 2008. p. 347.

20 BENAVIDES, Rebecca H. Summary of State "Price Gouging" Statutes and Regulations. Disponível em: <https://timedotcom.files.wordpress.com/2014/12/price-gouging-statutes.pdf>. Acesso em: 22 ago. 2017.

21 MARQUES, Cláudia Lima; BENJAMIN, Antônio Herman V. e MIRAGEM, Bruno. Comentários ao Código de Defesa do Consumidor. $7^{\text {a }}$ ed. rev., atual. e ampl. São Paulo: Revista dos Tribunais, 2013. p. 230 


\subsection{Apelação cível No 70044399210 - TJRS}

O Ministério Público do Estado do Rio Grande do Sul ajuizou uma Ação Civil Pública contra um posto de gasolina e os seus sócios após ter apurado que houve abusividade na fixação do preço da gasolina comum durante o feriado de Páscoa de 2004, o que teria ensejado prejuízo aos consumidores em geral. Ficou demonstrado no processo que o preço da gasolina comum foi aumentado de $\mathrm{R} \$ 2,07$, em 05.04.2004, para $\mathrm{R} \$ 2,17$ em 07/04/2004, quarta-feira, (dia anterior ao início do feriadão de Páscoa), tendo o valor sido reduzido para R \$ 2,05 após o feriado.

Os réus sustentaram que não caberia ao Ministério Público, tampouco ao Judiciário, determinar o que é preço excessivo, na medida em que os preços estão sujeitos ao regime de preços liberados. Foi arguido também que os preços e as margens de lucro praticadas estariam compatíveis com o mercado, com o regime de concorrência e com a carga tributária incidente sobre combustíveis, uma vez que a margem de $20 \%$ de lucro líquido permitida pela Lei $\mathrm{n}^{\circ}$ 1.521/51 (Lei da Economia Popular), art. $4^{\circ}$, alínea ' $b{ }^{22}$, não foi ultrapassada, destarte não estaria configurado qualquer ilegalidade no aumento praticado.

Em verdade, a lei referida pela defesa dispõe sobre crimes contra a economia popular, portanto o fato da conduta não se amoldar à previsão do tipo penal previsto nessa lei implica, tão somente, na impossibilidade de condenação pelo crime de usura pecuniária ou real. A margem de $20 \%$ não pode ser interpretada como um limite máximo aceitável para o aumento no preço de bens e serviços, a depender das características do produto e as circunstâncias do caso concreto uma elevação inferior a $10 \%$ já pode ser considerada abusiva, a exemplo do aumento praticado pelo posto de combustíveis.

Os réus foram incapazes de comprovar uma eventual elevação de custo operacional da empresa ré ou qualquer outro motivo relevante que explicasse o motivo do aumento brusco no preço da gasolina comum no feriado, ônus que lhe competia e do qual não se desincumbiu.

No caso em apreço, houve a desconsideração da personalidade jurídica para garantir a reparação dos danos causados, uma vez que a empresa ré havia encerrado suas atividades em 2007. Os sócios questionaram a aplicação do instituto, mas ele é perfeitamente aplicável ao caso por força do art. 28, caput, do Código de Defesa do Consumidor que inclui a ocorrência de abuso de direito como hipótese para proceder com a desconsideração da personalidade jurí$\operatorname{dica}^{23}$.

A 12a Câmara Cível do Tribunal de Justiça do Rio Grande do Sul manteve a decisão prolatada pelo juiz de primeiro grau para condenar solidariamente os réus ao pagamento de R\$ 45.000,00, a ser revertido ao Fundo Estadual de Defesa do Consumidor (FECON), e à repetição, em dobro, do indébito, em favor de cada consumidor lesado, no valor de $\mathrm{R} \$ 0,20$ por litro de gasolina comum adquirida no feriado de Páscoa de 2004.

\footnotetext{
22 Art. $4^{\circ}$. Constitui crime da mesma natureza a usura pecuniária ou real, assim se considerando: [...] b) obter, ou estipular, em qualquer contrato, abusando da premente necessidade, inexperiência ou leviandade de outra parte, lucro patrimonial que exceda o quinto do valor corrente ou justo da prestação feita ou prometida.

23 Art. 28. O juiz poderá desconsiderar a personalidade jurídica da sociedade quando, em detrimento do consumidor, houver abuso de direito, excesso de poder, infração da lei, fato ou ato ilícito ou violação dos estatutos ou contrato social. A desconsideração também será efetivada quando houver falência, estado de insolvência, encerramento ou inatividade da pessoa jurídica provocados por má administração. (grifo nosso)
} 


\subsection{Apelação cível No 200.2009.012293-4/002 - TJPB}

O Procon municipal de João Pessoa autuou um posto de gasolina ao reconhecer a abusividade no aumento do preço do litro da gasolina de $\mathrm{R} \$ 2,25$ para $\mathrm{R} \$ 2,589$ sem justa causa aparente, e aplicou multa administrativa no valor de $\mathrm{R} \$ 20.000,00$ (vinte mil reais). O empresário, dono do posto, contestou a multa e propôs uma ação na ação anulatória de ato administrativo para retirar a multa. Na primeira instância, a sua pretensão foi parcialmente acolhida e a multa foi reduzida para $\mathrm{R} \$ 5.000,00$ (cinco mil reais), mesmo após a redução significativa no valor da multa, o autor interpôs apelação para anular o auto sob o argumento de que a ordem jurídica brasileira consagra no art. 170 da Constituição Federal o princípio da livre iniciativa, não podendo sujeitar-se a qualquer restrição estatal quando não incidir em prática abusiva, como ocorre na situação em exame.

O tribunal, acertadamente, rechaçou este raciocínio e manteve a multa asseverando que o Estado deve promover um mínimo de proteção aos consumidores, assegurando que a liberdade econômica seja exercida conforme os ditames da justiça social e em consonância com os demais princípios insculpidos no art. 170 da Carta Magna, principalmente a defesa do consumidor.

O Estado tem o dever de promover a defesa dos hipossuficientes nas relações de consumo. As atuações dos órgãos públicos de defesa do consumidor como os Procons são essenciais para garantia da harmonia e equilíbrio nas relações de consumo, ao fiscalizar o mercado e combater as injustiças consumeristas através de autos de infração cumulados com multas, busca por soluções administrativas que desafoguem o judiciário e campanhas de conscientização eles contribuem sensivelmente para a formação de um mercado mais justo. A ação governamental constitui, inclusive, um dos princípios da Política Nacional de Relações de Consumo. ${ }^{24}$

\subsection{Processo $\mathrm{N}^{\circ}$ 0011729-23.2013.4.01.4100 - JFRO}

O Ministério Público Federal de Rondônia ingressou com uma Ação Civil Pública contra quatro companhias aéreas (TAM, AZUL, AVIANCA E GOL) devido ao aumento exacerbado no preço das passagens aéreas nos meses de férias (dezembro/2013 e janeiro/2014). O inquérito civil que serviu de base para a propositura da ação constatou diferenças de até $600 \%$ no preço das passagens, por exemplo, para o trecho Porto Velho - Brasília, a passagem chegava a $\mathrm{R} \$ 3.503,30$ (ida no dia 10 e volta no dia 12/01/2014), enquanto, um trecho de ida para o mesmo destino, no dia 15/01/2014 (quarta-feira), de menor procura, custava apenas $\mathrm{R} \$ 489,00$.

Os aumentos abusivos eram praticados por todas as companhias aéreas nos meses de férias e logo após o seu término os preços despencavam. A elevação nos preços não correspondia diretamente a uma maior procura nas passagens, haja vista que os preços foram reajustados mesmo com um grande número de assentos vagos. As passagens de Porto Velho para Curitiba no dia 15/12/2013 custavam R \$ 1.281,95 (Avianca); R\$ 1.296,85 (Azul); R \$ 932,85 (Gol); R\$

\footnotetext{
${ }^{24}$ Art. $4^{\circ}$ A Política Nacional das Relações de Consumo tem por objetivo o atendimento das necessidades dos consumidores, o respeito à sua dignidade, saúde e segurança, a proteção de seus interesses econômicos, a melhoria da sua qualidade de vida, bem como a transparência e harmonia das relações de consumo, atendidos os seguintes princípios:[...] II - ação governamental no sentido de proteger efetivamente o consumidor: a) por iniciativa direta; b) por incentivos à criação e desenvolvimento de associações representativas; c) pela presença do Estado no mercado de consumo; d) pela garantia dos produtos e serviços com padrões adequados de qualidade, segurança, durabilidade e desempenho.
} 
1.845,95 (TAM), já para o dia 07/02/2014 as passagens voltavam a um patamar normal custando, respectivamente: $\mathrm{R} \$ 545,95 ; \mathrm{R} \$ 516,85 ; \mathrm{R} \$ 407,85$ e $\mathrm{R} \$ 375,95$.

Diante desse quadro, o Ministério Público Federal requereu a condenação das companhias aéreas para que estas, nos meses de alta demanda, em especial dezembro/2013, janeiro/ 2014 e julho/2014, passem a cobrar o valor máximo de até 50\% acima das tarifas disponíveis para fevereiro/2014.

O pedido de limitar o aumento de preços pode soar estranho, haja vista que o período de preços tabelados no Brasil já é passado. Contudo, o país também não adota um liberalismo absoluto, ou seja, é possível a intervenção do mercado para regular a economia. Registre-se que aviação comercial constitui um serviço público federal ofertado por empresas privadas através de concessões e reguladas pela ANAC (Agência Nacional de Aviação Civil). Especialmente na região Norte do país onde não há uma malha rodoviária ou ferroviária desenvolvida, a aviação comercial ganha uma importância ainda maior para a população que precisa fazer viagens para rever familiares que moram em outras regiões ou mesmo a trabalho.

De tal forma que as companhias aéreas não podem explorar a necessidade premente de viajar dos consumidores para aumentar arbitrariamente os seus lucros, o que, como exposto anteriormente, constitui infração à ordem econômica nos termos do art. 36, inciso III, da Lei n. 12.529/2011. Aumentos nas tarifas de 400\%, 500\% são totalmente desproporcionais, mesmo se tratando de meses com maior demanda por passagens aéreas.

O juiz federal da $2^{\text {a }}$ Vara Federal da Seção Judiciária do Estado de Rondônia acolheu o pedido de liminar para limitar a elevação dos preços em $50 \%$ nos meses de pico, decisão que foi posteriormente confirmada. Ao fundamentar sua posição, o magistrado destacou que: "a inexistência de previsão do limite tarifário disciplinado pelo órgão regulador não dá o condão para que as rés arbitrem de forma desarrazoada o valor das passagens aéreas, sob o manto protetivo de que a 'mão invisível do mercado' é que deve guiar o valor da tarifa." Ficou claro que empresas aéreas estavam abusando do seu poder econômico e da essencialidade do serviço para os consumidores de Rondônia.

\subsection{Apelação cível $N^{\circ} 20120110688513$ - $3^{\text {a }}$ TURMA RECURSAL DOS JUIZADOS ESPECIAIS DO DISTRITO FEDERAL}

Nesse caso, um consumidor ingressou com uma ação no juizado especial no Distrito Federal contra uma empresa que organizava um show. $\mathrm{O}$ autor havia adquirido seu ingresso pelo telefone e foi cobrada uma taxa equivalente a $20 \%$ do valor do ingresso sem que ele usufruísse qualquer serviço adicional como entrega em domicílio do ingresso. A Turma Recursal confirmou a decisão inicial que considerou a prática abusiva, uma vez a empresa não tinha nenhum custo adicional na venda via call centers em relação às vendas nas bilheterias, ademais a fixação da taxa de $20 \%$ sobre o valor dos ingressos em detrimento de uma taxa fixa deixou ainda mais claro que a prática era abusiva e aumento de preço injustificado. A empresa foi condenada a restituir os valores pagos em dobro conforme os ditames do art. 42 do Código de Defesa do Consumidor. 


\subsection{Processo $\mathrm{N}^{\circ}$ 023.07.139894-8 TJSC}

Os torcedores de futebol que desejam acompanhar seus times quando eles jogam fora de casa, constantemente, são vítimas da prática abusiva do time mandante de elevar o preço dos ingressos para os visitantes. Torcedores desfrutam do mesmo espetáculo em condições praticamente idênticas, mas são obrigados a pagar um ingresso por um valor significativamente superior aos torcedores dos times da casa, o que também caracteriza uma violação a um dos direitos básicos do consumidor: a igualdade nas contratações ${ }^{25}$.

Neste processo, o Ministério Público estadual de Santa Catarina conseguiu uma liminar contra o time do Avaí Futebol Clube que estava cobrando valores distintos para a sua torcida e da torcida do Figueirense Futebol Clube, $\mathrm{R} \$ 20,00$ e $\mathrm{R} \$ 50,00$ respectivamente, para locais que oferecem as mesmas comodidades e visão do campo.

Como se pode depreender dos julgados expostos neste trabalho, Ministério Público teve, na maioria dos casos, participação direta para proteção do direito dos consumidores ao promover Ações Civis Públicas. Hugo Mazzilli ${ }^{26}$ destaca as vantagens da utilização dessa ação coletiva, quais sejam: acesso à justiça mais eficaz, evita decisões contraditórias, obter economia processual etc. Destarte, promotorias proativas na proteção do consumidor podem ter um impacto muito positivo para o equilíbrio do mercado por terem a possibilidade de conseguir decisões judicias que podem ter efeito erga omnes em contrapartida às ações individuais que resguardam os direitos de um número limitado de cidadãos e, via de regra, tem menos recursos para instruir o processo com provas.

\section{CONSIDERAÇÕES FINAIS}

Pode-se constatar ao longo do estudo realizado que um direito subjetivo exercido em desconformidade com seus preceitos axiológicos pode gerar atos antijurídicos quando prejudicam terceiros. A teoria do abuso de direito evoluiu junto com a concepção de que o direito está além das normas positivadas e foi incorporada ao Código de Defesa do Consumidor onde há um subsistema do abuso de direito englobando as cláusulas contratuais, práticas comerciais e a publicidade.

A proibição da elevação sem justa causa dos preços está respaldada pelo fato de a liberdade econômica estar condicionada aos ditames da justiça social, sendo a defesa do consumidor um dos princípios da ordem econômica, consoante dispõe o art. 170, V da Constituição Federal. O motivo do aumento dos preços terá de ser devidamente exposto e justificado, o que é ainda mais necessário nos casos em que o bem ou serviço tiver caráter essencial.

Aos fornecedores não é conferido a possibilidade de explorar a situação de vulnerabilidade inerente aos consumidores para aumentar seus lucros, caso eles empreguem práticas desleais, a frágil harmonia do mercado estará comprometida, prejudicando os direitos básicos dos consumidores. Haverá elevação sem justa causa então quando o aumento do preço fugir dos parâmetros de razoabilidade e boa-fé sem qualquer justificativa ou fato relevante que tenha tornado a produção ou venda do produto mais cara de forma a causar danos aos consumidores.

\footnotetext{
${ }^{25}$ Art. $6^{\circ}$ São direitos básicos do consumidor:

$[\ldots]$

II - a educação e divulgação sobre o consumo adequado dos produtos e serviços, asseguradas a liberdade de escolha e a igualdade nas contratações; (grifo nosso)

${ }^{26}$ MAZZILLI, Hugo Nigro. A defesa dos interesses difusos em juízo: meio ambiente, consumidor, patrimônio cultural, patrimônio público e outros interesses. 20. ed. rev., ampl. e atual. São Paulo: Saraiva, 2007. p. 172
} 


\section{REFERÊNCIAS}

ALMEIDA, João Batista de. A proteção jurídica do consumidor. $7^{a}$ ed. São Paulo: Saraiva, 2009;

BENAVIDES, Rebecca H. Summary of State "Price Gouging" Statutes and Regulations. Disponível em: 〈https://timedotcom.files.wordpress.com/2014/12/price-gouging-statutes.pdf〉. Acesso em: 22 ago. 2017.

BRASIL. Tribunal de Justiça da Paraíba. Apelação Cível no 200.2009.012293-4/002, Décima Segunda Câmara Cível, Relator: Juiz Marcos William de Oliveira (convocado), Data de Julgamento: 26/04/2012;

BRASIL. Tribunal de Justiça de Santa Catarina. Processo n ${ }^{\circ}$ 023.07.139894-8/2007;

BRASIL. Tribunal de Justiça do Distrito Federal e Territórios. Acórdão no $\mathbf{6 8 5 3 2 6}$, 20120110688513ACJ, $3^{\text {a }}$ Turma Recursal dos Juizados Especiais do Distrito Federal, Relator: Evandro Neiva De Amorim, Data de Julgamento: 11/06/2013;

BRASIL. Tribunal de Justiça do Rio Grande do Sul. Apelação Cível no 70005127527, Relator: Des. Antonio Carlos Stangler Pereira, 8 a Câm. Cível, Data de Julgamento: 26/04/2012;

BRASIL. Tribunal Regional Federal da $1^{\mathrm{a}}$ Região Processo no 0011729-23.2013.4.01.4100 - $2^{\mathrm{a}}$ Vara Federal da Seção Judiciária de Rondônia;

BUCHAIN, L. C. Os objetivos do direito da concorrência em face da ordem econômica nacional. Cadernos do Programa de Pós-Graduação em Direito - PPGDIR./UFRGS, v. 9, p. 225-262, 2014.

CUETO-RUA, Julio C. Abuse of Rights. Louisiana Law Review. Baton Rouge, v. 35, n. 5, pp. 965-1013, 1975. Disponível em <http://digitalcommons.law.lsu.edu/lalrev/vol35/iss5/3>. Acesso em: 19 ago. 2017;

CUNHA DE SÁ, Fernando Augusto. Abuso do direito. Coimbra: Almedina, 2005;

FERNANDES NETO, Guilherme. Cláusulas, prática e publicidades abusivas. $1^{\mathrm{a}}$ ed. São Paulo : Atlas. 2012;

FILOMENO, José Geraldo Brito. Manual de direitos do consumidor. $9^{\text {a }}$ ed. São Paulo : Atlas 2007.

GRINOVER, Ada Pellegrini; BENJAMIN, Antônio Herman V.... [et al.]. Código brasileiro de defesa do consumidor: comentado petos autores do anteprojeto. 11. ed. Rio de Janeiro: Forense, 2017;

MARQUES, Cláudia Lima; BENJAMIN, Antônio Herman V. e MIRAGEM, Bruno. Comentários ao Código de Defesa do Consumidor. $7^{\mathrm{a}}$ ed. rev., atual. e ampl. São Paulo: Revista dos Tribunais, 2013.

MAZZILLI, Hugo Nigro. A defesa dos interesses difusos em juízo: meio ambiente, consumidor, patrimônio cultural, patrimônio público e outros interesses. 20. ed. rev., ampl. e atual. São Paulo: Saraiva, 2007;

MIRAGEM. Bruno. Curso de Direito do Consumidor. $7^{\mathrm{a}}$ ed. rev. atual. e ampl. - São Paulo: Editora Revista dos Tribunais, 2018; 
MIRAGEM. Bruno. O ilícito e o abusivo: propostas para uma interpretação sistemática das práticas abusivas nos 25 anos do Código de Defesa do Consumidor. Revista de Direito do Consumidor, v. 104, p. 99-130, 2016.

MELLO, Heloisa Carpena Vieira de. O abuso do direito no Código de 2002: relativização de direitos na ótica civil constitucional. In: TEPEDINO, Gustavo (Org.). A parte geral do novo código civil: estudos na perspectiva civil-constitucional. 2. ed. rev. atual. Rio de Janeiro : Renovar, 2003;

NUNES, Luiz Antônio Rizzatto. Curso de Direito do Consumidor. 4. ed. rev. São Paulo: Saraiva, 2009.

STEINER, Eva. French Law : A Comparative Approach. New York : Oxford University Press, 2010;

TAVARES, André Ramos. Direito constitucional econômico. 2.ed. São Paulo: Ed. Método, 2006.

TEPEDINO, Gustavo. Temas de Direito Civil. ed 4a . Rio de Janeiro : Renovar, 2008.

UNIÃO EUROPEIA. Directiva 2005/29/CE do Parlamento Europeu e do Conselho da União Europeia de 11 de Maio de 2005. Disponível em: <http://eur-lex.europa.eu/legalcontent/PT/TXT/?uri=uriserv:OJ.L_.2005.149.01.0022.01.POR>. Acesso em: 21 ago. 2017.

ZWOLINSKI, Matt. The ethics of price gouging. Business Ethics Quarterly, v. 18, n. 03, pp. 347-378, 2008.

Recebido em: $1^{\circ}$ mar. 2018.

Aceito em: 30 out. 2018. 